\section{Primed Acclimation of Papaya Increases Short-term Water Use But Does Not Confer Long-term Drought Tolerance}

\author{
Christopher Vincent ${ }^{1}$ \\ Horticultural Sciences Department, Citrus Research and Education Center, \\ University of Florida, 700 Experiment Station, Lake Alfred, FL 33850
}

Diane Rowland

Agronomy Department, University of Florida, P.O. Box 110500, Gainesville, FL 32611

\author{
Bruce Schaffer \\ Horticultural Sciences Department, Tropical Research and Education \\ Center, University of Florida, 18905 S.W. 280 Street, Homestead, FL \\ 33031
}

Additional index words. Carica papaya, regulated deficit irrigation, stress memory

\begin{abstract}
Primed acclimation (PA) is a regulated deficit irrigation (RDI) strategy designed to improve or maintain yield under subsequent drought stress. A previous study showed photosynthetic increases in papaya in response to a PA treatment. The present study was undertaken to test the duration of the PA effect when papaya plants were challenged with severe drought stress. Potted plants were stressed at 1, 2, and 3 months after conclusion of a $P A$ treatment consisting of 3 weeks at soil water tension (SWT) of $-20 \mathrm{kPa}$. Measurements included leaf gas exchange, root growth, and organ dry mass partitioning. PA did not reduce net $\mathrm{CO}_{2}$ assimilation $(A)$ during the deficit period. At the end of the $P A$ period, total dry matter accumulation per plant and for each organ was unaffected, but proportional dry matter partitioning to roots was favored. After resuming full irrigation, $A$ increased and whole plant water use was more than doubled in PA-treated plants. However, water use and $\boldsymbol{A}$ of PA-treated plants decreased to reconverge with those of control plants by 6 weeks after the PA treatment. Over the course of the study, PA plants maintained lower stem height to stem diameter ratios, and shorter internode lengths. However, these changes did not improve photosynthetic response to any of the water-deficit treatments. We conclude that papaya exhibits some signs of stress memory, but that rapid short-term acclimation responses dominate papaya responses to soil water deficit.
\end{abstract}

Combined factors of climate change and population growth are expected to put increasing strain on agricultural water resources. Although traditional efforts aimed at improving crop tolerance to water scarcity focus on responses to static levels of water deficit, increasing attention is being given to the capacity of plants to acclimate under highly variable environmental conditions (Smith et al., 2015). PA is a crop management approach that uses specialized RDI to preacclimate plants to water-deficit conditions (Rowland et al., 2012). PA treatments are targeted both to phenological stages and to soil water levels with the goal of inducing beneficial physiological responses without causing a growth-reducing stress (Rowland

Received for publication 22 Nov. 2016. Accepted for publication $20 \mathrm{Jan} .2017$.

We thank Ana Vargas and Raiza Castillo for their help with data collection and plant maintenance.

${ }^{1}$ Corresponding author. E-mail: civince@ufl.edu. et al., 2012). Although in the United States papaya plantings are generally irrigated, the producing region in Florida lies between an urban area with high demand for water, and a protected natural area facing water quality challenges due to agricultural irrigation (Williamson and Crane, 2010). This has led to increasing pressure to reduce horticultural water use (Migliaccio et al., 2006). Thus, PA may be useful as a water-conserving irrigation practice. A PA treatment in papaya was previously developed by targeting a rootzone water potential (about $-30 \mathrm{kPa}$ ) shown to induce a stomatal response without greatly reducing photosynthesis (Vincent et al., 2015). PA treatments have been successful in reducing irrigation water inputs and in maintaining yield under water deficits for potato (Solanum tuberosum L.; Ramírez et al., 2015) and peanut (Arachis hypogaea L.; Rowland et al., 2012).

PA may induce stress memory, which consists of differential responses to subsequent stresses induced by prior stress exposure.
Some stress memory mechanisms comprise induced latent capacity for hypersensitive responses to subsequent water deficit. For example, in tall fescue, repeated stresses induced increasing biochemical responses during each repeated drought stress, but during periods of adequate water availability, no biochemical differences between previously stressed and not previously stressed plants were measured (Hu et al., 2015). Another potential class of stress memory mechanisms is morphological adjustments that confer tolerance of subsequent stresses (Ramírez et al., 2015; Rowland et al., 2012). Much of the literature that addresses stress memory explicitly considers relationships between extreme stresses (Pastor et al., 2013). However, PA studies have indicated stress memory was induced by mild-to-moderate levels of stress in peanut and potato (Ramírez et al., 2015; Rowland et al., 2012).

Despite expanding knowledge about the potential of PA in agronomic crops, this approach has not been tested to any great degree in fruit or vegetable crops, particularly those that are considered biennial or perennial. Papaya was chosen as an ideal priming candidate because of its morphological and physiological plasticity (Buisson and Lee, 1993; Clemente and Marler, 1996). A prior study of papaya showed a 3-week PA treatment induced increased net $\mathrm{CO}_{2}$ assimilation $(A)$, stomatal conductance $\left(g_{\mathrm{S}}\right)$, and photochemical efficiency but raised questions about the duration of these effects of $\mathrm{PA}$, and the interaction of PA with more severe subsequent deficits (Vincent et al., 2015). The objective of the present study was to determine whether PA induced a stress memory in papaya in terms of water-deficit tolerance and to observe potential mechanisms for the post-PA increase in $A, g_{\mathrm{S}}$, and transpiration. The hypotheses of this study were 1) PA of papaya induces stress memory, defined as a differential response (positive or negative) to subsequent water deficits between primed and unprimed plants; 2) stress memory improves papaya drought tolerance, defined as maintenance of dry matter accumulation or $A$ during water deficits; and 3) PA-induced stress memory diminishes over time.

\section{Materials and Methods}

Plant material. 'Red Lady' papaya seeds were planted in a greenhouse in potting trays on 15 Aug. 2014 and watered daily. Plants were transplanted on 10 Oct. 2014 into 38-L pots with ProMix ${ }^{\circledR}$ potting medium (Premier Tech, QC, Canada). The study occurred in a greenhouse with a polymer plastic roof and a shade net with $\approx 60 \%$ transmittance of photosynthetically active radiation [PAR; measured with a quantum sensor and data logger (LI-COR, Inc., Lincoln, NE)] at midday on four sides. Before transplanting, acrylic minirhizotron tubes $(5.2$ and $5.8 \mathrm{~cm}$ inner and outer diameter, respectively) were installed into each pot at a horizontal angle $\approx 15 \mathrm{~cm}$ from the bottom of each pot. 
Sections of minirhizotron tubes outside the pots were painted black to prevent the entry of light, with a second coat of white paint and reflective insulation to prevent excessive heating. When not in use, the tubes were capped on each end with polyvinyl chloride caps to prevent entry of water or foreign material. When not undergoing a priming or deficit treatment, each plant was irrigated daily with a microsprinkler with a volume of $1.04 \mathrm{~L}$ at a rate of $0.13 \mathrm{~L} \cdot \mathrm{min}^{-1}$, an amount previously determined to be sufficient for soil water content to reach or exceed field capacity.

Experimental design. The experiment was arranged as a randomized complete block design with six blocks and eight treatments. Blocks were arranged spatially in rows of pots, and plants were assigned to blocks based on stem diameter. The experimental unit was an individual plant in a single pot. The treatment structure was a factorial with PA and water deficit as the two factors. PA had two levels: 1) primed acclimation ( $\mathrm{P}$, described below) and 2) no primed acclimation (NP). Water deficit had four levels: a water deficit imposed at $\approx 1,2$, or 3 months after $\mathrm{P}$ (Deficits 1, 2, 3, respectively), and no water deficit (Deficit 0). An additional six replications of the PA factor were included for destructive sampling immediately following the PA period.

Treatments. To impose the PA treatment, microsprinklers were removed, and each pot was allowed to dry to $-20 \mathrm{kPa}$, as measured by tensiometers (Irrometer Inc., Salinas, CA) installed in each pot. This level of SWT had been determined sufficient to induce a primed response in a previous study (Vincent et al., 2015). After reaching $-20 \mathrm{kPa}$, the pots were weighed daily for 3 weeks and watered each day by hand with sufficient irrigation volume to achieve SWT of $-20 \mathrm{kPa}$. Once the PA treatment ended, deficit treatments were imposed by shutting off irrigation until 1 week after the potting medium reached about -40 $\mathrm{kPa}$ as measured by tensiometers. This resulted in different durations among each of the deficit treatments with Deficits 1,2, and 3 lasting about 6, 4, and 5 weeks, respectively. During the first soil drying treatment period (Deficit 1, 11 Nov. 2014 to 24 Dec. 2014), pots of the P plants within the Deficit 1 treatment began drying faster than NP plants. Therefore, to avoid different degrees of deficit between P and NP plants, $\mathrm{P}$ plants were hand watered daily to achieve the mean water content of the NP plants. Tensiometers were monitored during Deficits 2 and 3, but no differences in water use were observed between P and NP treatments. Thus, supplemental water was not provided during Deficits 2 and 3. The study was not repeated.

Variables measured. Plant variables were measured at the end of the priming period (6 Nov. 2014) and during the last $3 \mathrm{~d}$ of each deficit period (22 Dec. 2014, 19 Jan. 2015, and 27 Feb. 2015). Measurements included leaf chlorophyll index, leaf gas exchange, nondestructive plant growth variables, root system architecture, and tissue dry weights
Table 1. Priming treatment means of destructive harvest variables of 'Red Lady' papaya plants samples at end of priming treatment ( $28 \mathrm{~d}$ after transplanting). Primed: maintained at $-20 \mathrm{kPa}$ for 3 weeks 1 month after transplanting; Not primed: watered daily to saturation.

\begin{tabular}{|c|c|c|c|c|c|}
\hline \multirow[b]{2}{*}{ Treatment } & \multicolumn{2}{|c|}{ Not primed } & \multicolumn{2}{|c|}{ Primed } & \multirow[b]{2}{*}{$P$ value } \\
\hline & Mean & SE & Mean & $\mathrm{SE}$ & \\
\hline Total DW & 41.4 & 2.5 & 44.7 & 5.5 & 0.27 \\
\hline Stem DW & 13.4 & 0.6 & 12.9 & 1.7 & 0.57 \\
\hline Root DW & 16.5 & 1.4 & 19.5 & 2.1 & 0.15 \\
\hline Root:shoot & $1.2 \mathrm{~b}$ & 0.1 & $1.5 \mathrm{a}$ & 0.1 & 0.04 \\
\hline Root:LA & $6.2 \mathrm{~b}$ & 0.3 & $7.5 \mathrm{a}$ & 0.2 & 0.05 \\
\hline $\begin{array}{l}\text { Leaves } \\
\text { per plant }\end{array}$ & 12 & 0.7 & 12 & 0.9 & 0.48 \\
\hline Total LA & 2,675 & 167 & 2,638 & 320 & 0.11 \\
\hline Mean LA & 223.4 & 10.4 & 217.6 & 17.6 & 0.58 \\
\hline SLW & 3.55 & 0.06 & 3.77 & 0.11 & 0.60 \\
\hline
\end{tabular}

$\overline{\mathrm{DW}}=$ dry weight, LA = leaf area, SLW = specific leaf weight; units for DWs are g, root:LA are mg root/ $\mathrm{cm}^{2}$ leaf, LA per plant and mean LA are $\mathrm{cm}^{2}$; and SLW are $\mathrm{mg} \cdot \mathrm{cm}^{-2}$. Means followed by the same letter are significantly different at $P=0.05$ using Bonferroni means comparison test.

Table 2. Priming treatment means of destructive harvest variables of 'Red Lady' papaya plants sampled at end of study (173 d after transplanting). Primed: maintained at $-20 \mathrm{kPa}$ for 3 weeks 1 month after transplanting; Not primed: watered daily to saturation.

\begin{tabular}{|c|c|c|c|c|c|}
\hline \multirow[b]{2}{*}{ Priming } & \multicolumn{2}{|c|}{ Not primed } & \multicolumn{2}{|c|}{ Primed } & \multirow[b]{2}{*}{$P$ value } \\
\hline & Mean & SE & Mean & SE & \\
\hline Total DW & 156.5 & 7.0 & 164.4 & 5.8 & 0.60 \\
\hline Stem DW & 66.1 & 2.6 & 67.6 & 2.0 & 0.79 \\
\hline Root DW & 75.2 & 4.1 & 81.6 & 3.9 & 0.26 \\
\hline Root:shoot & $0.92 \mathrm{~b}$ & 0.03 & $0.98 \mathrm{a}$ & 0.03 & 0.008 \\
\hline Root:LA & $23.1 \mathrm{~b}$ & 1.2 & $26.3 \mathrm{a}$ & 1.5 & 0.006 \\
\hline $\begin{array}{l}\text { Leaves } \\
\text { per plant }\end{array}$ & 4.1 & 0.2 & 4.1 & 0.3 & 0.84 \\
\hline Total LA & 3,431 & 135 & 3,120 & 135 & 0.921 \\
\hline Mean LA & 459 & 23 & 421 & 20 & 0.78 \\
\hline SLW & 4.9 & 0.1 & 5.1 & 0.2 & 0.09 \\
\hline
\end{tabular}

$\mathrm{DW}=$ dry weight; LA = leaf area; SLW = specific leaf weight; units for DWs are g, root:LA are mg root/ $\mathrm{cm}^{2}$ leaf, LA per plant and mean LA are $\mathrm{cm}^{2}$, and SLW are $\mathrm{mg} \cdot \mathrm{cm}^{-2}$. Means followed by the same letter are significantly different at $P=0.05$ using a Bonferroni means comparison test.

Table 3. Dry weights of 'Red Lady' papaya plants samples at harvest ( $173 \mathrm{~d}$ after transplanting). Each deficit treatment lasted $\approx 1$ month. Deficit 1: 3 months after transplanting, Deficit 2: 4 months after transplanting, Deficit 3: 5 months after transplanting, Control: watered daily to saturation.

\begin{tabular}{|c|c|c|c|c|c|c|c|c|c|}
\hline \multirow[b]{2}{*}{ Deficit } & \multicolumn{2}{|c|}{ Control } & \multicolumn{2}{|c|}{ Deficit 1} & \multicolumn{2}{|c|}{ Deficit 2} & \multicolumn{2}{|c|}{ Deficit 3} & \multirow[b]{2}{*}{$P$ value } \\
\hline & Mean & SE & Mean & SE & Mean & SE & Mean & SE & \\
\hline Total DW & $178.9 \mathrm{a}$ & 9.26 & $152.1 \mathrm{~b}$ & 8.03 & $164.3 \mathrm{ab}$ & 8.04 & $145.6 \mathrm{~b}$ & 8.49 & 0.02 \\
\hline Stem DW & $74.3 \mathrm{a}$ & 2.89 & $62.4 \mathrm{~b}$ & 2.92 & $67.1 \mathrm{ab}$ & 3.34 & $63.3 \mathrm{~b}$ & 2.96 & 0.02 \\
\hline Root DW & $88.4 \mathrm{a}$ & 6.68 & $76.7 \mathrm{ab}$ & 4.65 & $80.8 \mathrm{ab}$ & 4.88 & $67 \mathrm{~b}$ & 4.82 & 0.03 \\
\hline Root:shoot & $0.97 \mathrm{ab}$ & 0.06 & $1.02 \mathrm{a}$ & 0.03 & $0.97 \mathrm{ab}$ & 0.05 & $0.85 \mathrm{~b}$ & 0.03 & 0.05 \\
\hline Root:LA & $27.9 \mathrm{a}$ & 1.85 & $24.84 \mathrm{ab}$ & 2.16 & $24.7 \mathrm{ab}$ & 2.11 & $20.9 \mathrm{~b}$ & 1.33 & 0.05 \\
\hline $\begin{array}{c}\text { Leaves per } \\
\text { plant }\end{array}$ & 4.3 & 0.4 & 4.3 & 0.4 & 3.6 & 0.4 & 4.2 & 0.4 & 0.65 \\
\hline Total LA & 3,168 & 194 & 3,129 & 182 & 3,439 & 207 & 3,361 & 203 & 0.59 \\
\hline Mean LA & 419 & 27 & 426 & 35 & 454 & 33 & 460 & 32 & 0.60 \\
\hline SLW & 5.20 & 0.24 & 4.97 & 0.14 & 4.83 & 0.26 & 5.04 & 0.15 & 0.58 \\
\hline
\end{tabular}

$\mathrm{DW}=$ dry weight, $\mathrm{LA}=$ leaf area, SLW = specific leaf weight; units for DWs are g, root:LA are mg root/ $\mathrm{cm}^{2}$ leaf, LA per plant and mean LA are $\mathrm{cm}^{2}$, and SLW are $\mathrm{mg} \cdot \mathrm{cm}^{-2}$. Means followed by the same letter are significantly different at $P=0.05$ using Bonferroni means comparison test.

Table 4. Repeated measures analyses of variance of relative growth of stem height, relative growth of stem diameter, and height:diameter ratio of 'Red Lady' papaya.

\begin{tabular}{|c|c|c|c|c|c|c|c|c|}
\hline \multirow[b]{2}{*}{ Effect } & \multicolumn{2}{|r|}{ df } & \multicolumn{2}{|c|}{ Stem diam } & \multicolumn{2}{|c|}{ Stem ht } & \multicolumn{2}{|c|}{ Ht:diam } \\
\hline & Numerator & Denominator & F value & $P$ value & F value & $P$ value & F value & $P$ value \\
\hline Priming & 1 & 44 & 2.42 & 0.13 & 2.73 & 0.11 & 9.81 & 0.003 \\
\hline Deficit & 1 & 44 & 5.69 & 0.02 & 11.75 & 0.001 & 0.62 & 0.44 \\
\hline Date & 3 & 130 & 369.00 & $<0.0001$ & 206.99 & $<0.0001$ & 124.29 & $<0.0001$ \\
\hline Priming $\times$ deficit & 1 & 44 & 0.08 & 0.78 & 0.31 & 0.58 & 0.60 & 0.44 \\
\hline Priming $\times$ date & 3 & 130 & 11.00 & $<0.0001$ & 5.94 & 0.0008 & 3.06 & 0.03 \\
\hline Deficit $\times$ date & 3 & 130 & 7.74 & 0.0001 & 5.58 & 0.001 & 0.42 & 0.74 \\
\hline $\begin{array}{l}\text { Priming } \times \\
\quad \text { deficit } \times \text { date }\end{array}$ & 3 & 130 & 0.55 & 0.65 & 1.33 & 0.27 & 0.74 & 0.53 \\
\hline
\end{tabular}




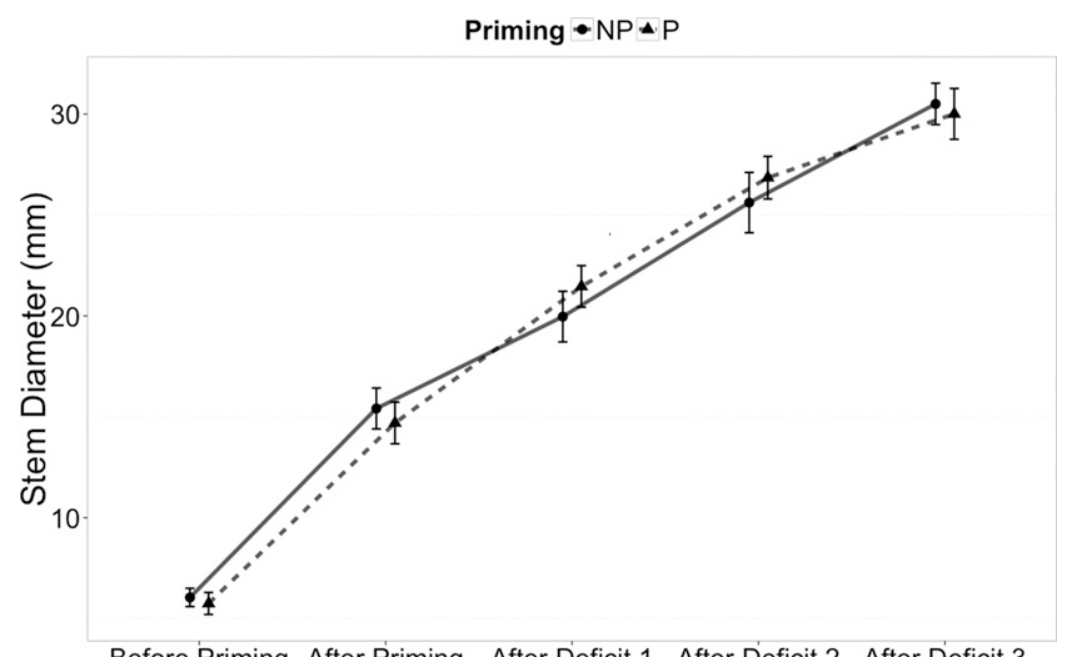

Before Priming After Priming After Deficit 1 After Deficit 2 After Deficit 3

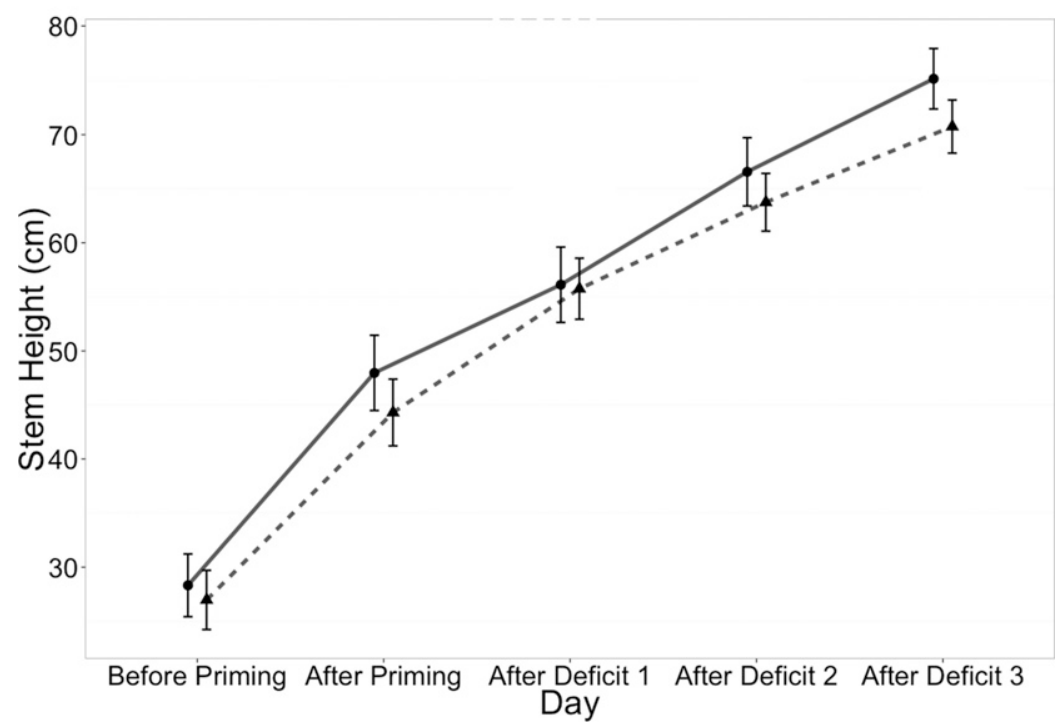

Fig. 1. Height and diameter of primed (P) and unprimed (NP) plants over priming memory study. Error bars represent $95 \%$ confidence intervals.

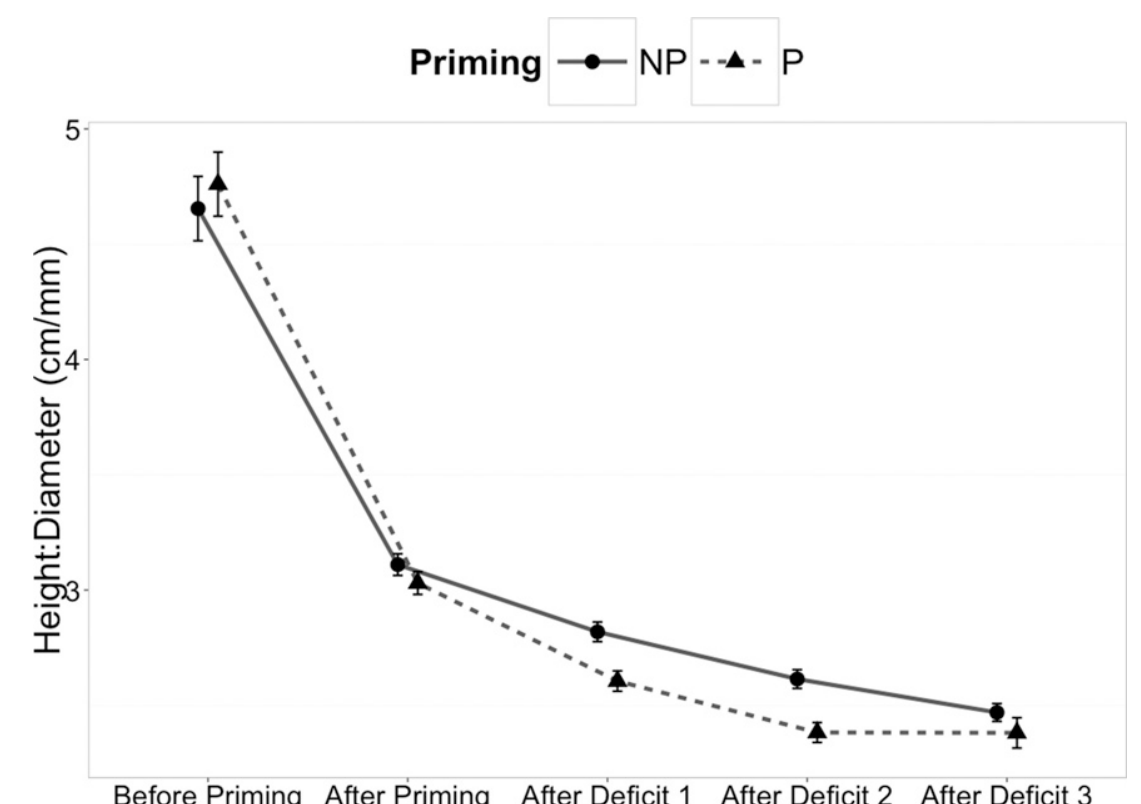

Fig. 2. Height:diameter of primed (P) and unprimed (NP) plants over priming memory study. Error bars represent $95 \%$ confidence intervals.
(DW). Leaf chlorophyll index was determined using a digital camera and GreenIndex + board and smartphone application to approximate SPAD values (Spectrum Technologies, Inc., Aurora, IL; Rorie et al., 2011). $A, g_{\mathrm{S}}$, and transpiration $(E)$ were measured on the first fully expanded leaf (generally fourth or fifth leaf from the apex) with a portable infrared gas analyzer (Ciras-3; PP Systems, Amesbury, MA) between 1000 and $1200 \mathrm{HR}$, with in-cuvette conditions of $390 \mathrm{ppm} \mathrm{CO}_{2}$ and $1000 \mu \mathrm{mol}$ quanta $/ \mathrm{m}^{2} / \mathrm{s}$ of PAR. Nondestructive plant growth variables included stem height and diameter measured $10 \mathrm{~cm}$ above the surface of the potting media. The stem height:diameter ratio was calculated from these measurements. Root architectural variables included total root length (TRL), total surface area (TSA), and average diameter and were measured using a minirhizotron system to capture images (Bartz Technology Corporation, Carpinteria, CA). Images were then analyzed using the WinRhizo TRON software by hand tracing individual root segments on each image, resulting in measures for TRL and TSA for each pot (Regent Instruments, QC, Canada). Additionally, root hairs were quantified in the minirhizotron images using a previously developed, partially automated method (Vincent et al., 2016). Tensiometers were installed in each pot (as mentioned above) during the imposition of water-deficit periods and SWT of the potting medium was recorded daily.

Plants were destructively harvested on one of two dates. The first occurred at the end of the priming treatment, but before reestablishing full irrigation [10 Nov. 2014, $40 \mathrm{~d}$ after transplanting (DAT)], with only the additional subset of plants harvested on this date. The second occurred at the end of the study (1 Apr. 2015, 173 DAT) when all remaining plants were harvested. Roots were washed, leaf area was measured, and leaves, stems, and roots were each dried separately at $60{ }^{\circ} \mathrm{C}$ for $72 \mathrm{~h}$ before weighing. Destructive measurements included leaf area per plant, average leaf area, and organ DW of leaves, stems, and roots. From these measurements, we calculated the ratio of DW of roots to aboveground organs (root:shoot), root DW to leaf area ratio $\left(\mathrm{mg} \cdot \mathrm{cm}^{-2}\right.$; root:LA), and specific leaf weight $\left(\mathrm{mg} \cdot \mathrm{cm}^{-2}\right)$. During Deficit 1, weighing each pot before and after watering each day enabled calculation of daily water use for these treatments.

Analyses. Stem diameter, height, and the height:diameter ratio, TRL, and TSA were analyzed as relative growth rates, calculated as the average relative daily growth from the previous measurement to the current measurement, for example:

Relative growth rate of height

$$
=\frac{\left(\frac{\text { Height }_{2}-\text { Height }_{1}}{\text { Height }_{1}}\right)}{\text { Date }_{2}-\text { Date }_{1}}
$$

Leaf chlorophyll index, $A, g_{\mathrm{S}}, E, \mathrm{DW}$, and LA were analyzed by two-way (Deficit $\times$ PA) 


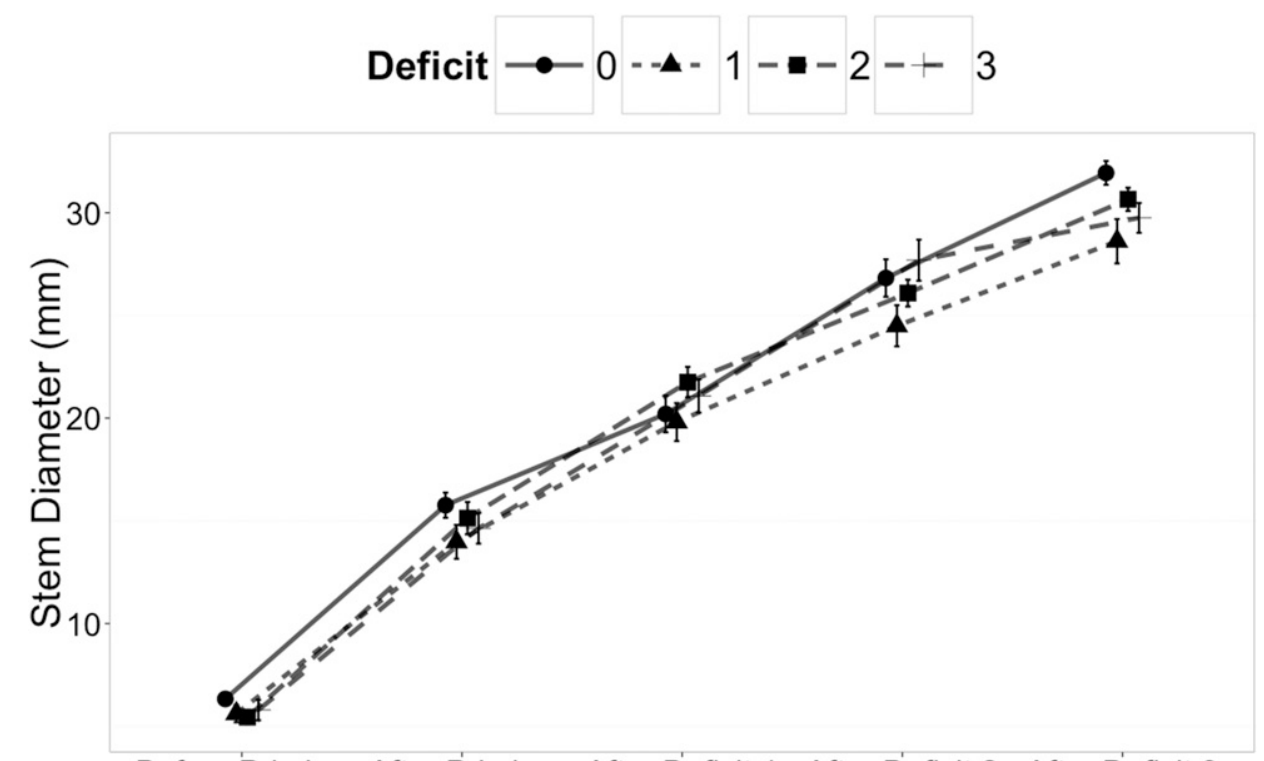

Before Priming After Priming After Deficit 1 After Deficit 2 After Deficit 3

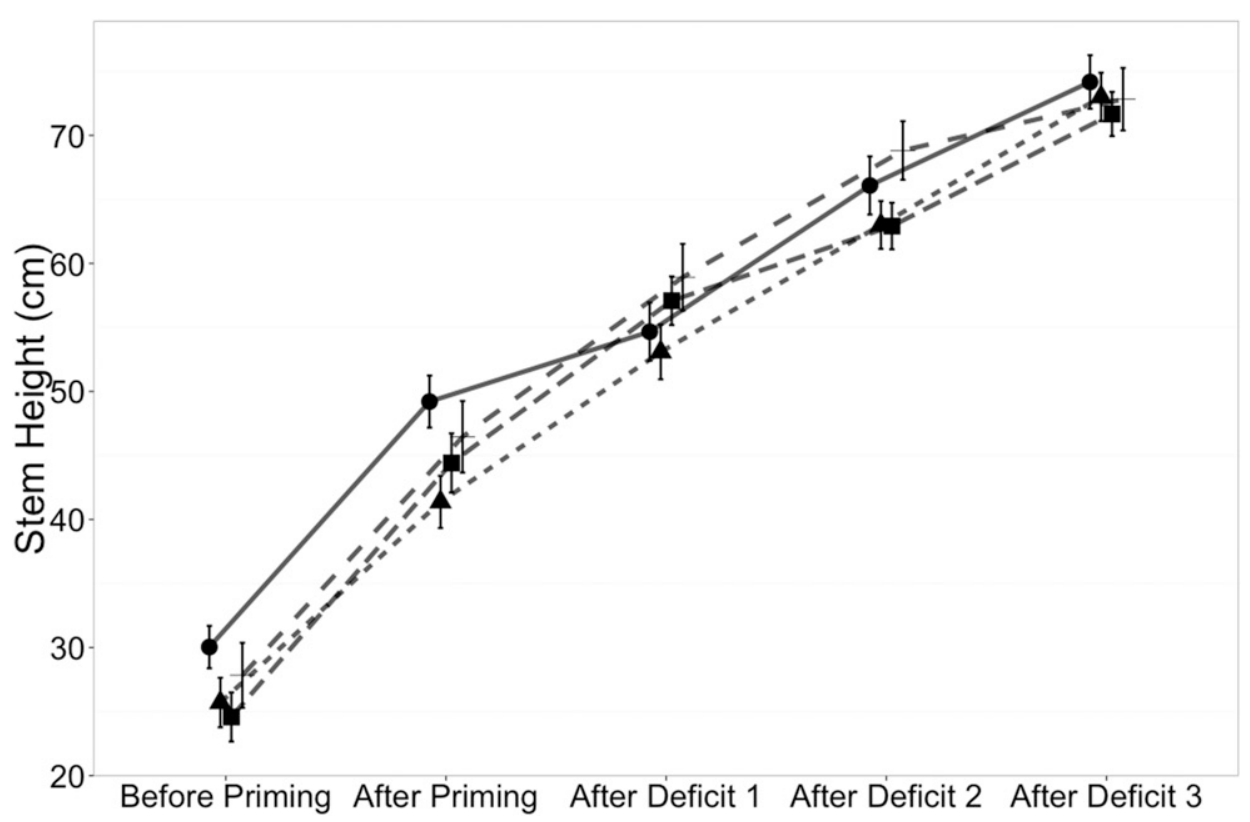

Fig. 3. Height and diameter of plants exposed to water-deficit treatments over priming memory study. Error bars represent $95 \%$ confidence intervals. Deficit 1: 3 months after transplanting, Deficit 2: 4 months after transplanting, Deficit 3: 5 months after transplanting, control: watered daily to saturation.

analyses of variance (ANOVAs) on each measurement date. Repeated measures models were fit using the nlme package in the R statistical program (Pinheiro et al., 2015), whereas nonrepeated measures ANOVAs were performed using the linear model command in the basic $\mathrm{R}$ package (R Core Team, 2016) and mean separations were generated using the agricolae package (de Mendiburu, 2015). Daily plant water loss (DWL) during Deficit 1 at varying SWT levels was fit with a linear model and tested with PA treatment (PA) as a fixed effect including potential interaction of priming with SWT. Only, Deficit 1 was used because, as mentioned above, differential DWL was only observed during Deficit 1. Thus the fixed-effects portion of the model was DWL = $\mathrm{PA}+\mathrm{SWT}+\mathrm{PA} \times \mathrm{SWT}$. Because of the observed effects of PA on root-related DW variables and the increase in water use after the imposition of the P treatment, only P and NP plants with the Deficit control (Deficit 0) were included in a one-way analysis of TRL, TSA, and root diameter to test the PA effect.

\section{Results}

At the end of the PA period ( $21 \mathrm{~d})$, no organ DWs nor leaf area variables were different between P and NP treatments. However, priming increased root:shoot and root: LA, despite having no effect on any of the component variables (root DW, shoot DW, leaf DW, or total LA; Table 1). In contrast, by the end of the experiment, the PA treatment only increased the root:LA ratio (Table 2). There were no interactions between PA and deficit treatments for leaf DW, root DW, stem $\mathrm{DW}$, total DW, total or average LA, root: shoot, or root:LA. There were, however, differences among deficit treatments for total DW, stem DW, root DW, root:shoot, and root:LA (Table 3). Total DW, stem DW, root DW, and root:LA ratio were either reduced relative to the control or were statistically similar among all treatments. Deficit 1 had the highest root:shoot and Deficit 3 the lowest, primarily due to a reduction of root DW in Deficit 3.

There were interactions between deficit and date for height and diameter as well as interactions between PA and date for height, diameter, and the height:diameter ratio. The relative increase of stem height and diameter was greater in P plants than NP plants during the period immediately following the 


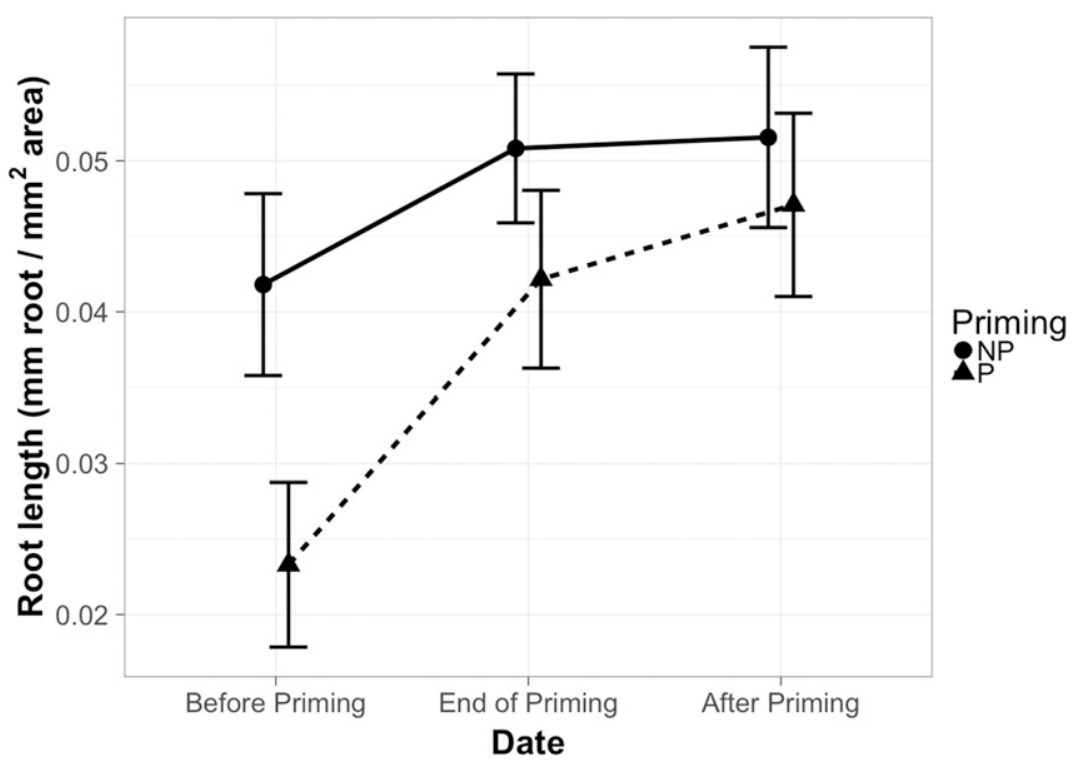

Fig. 4. Root length of 'Red Lady' papaya exposed to primed acclimation treatments. P: primed, NP: not primed. Error bars represent $95 \%$ confidence intervals.

priming treatment (Deficit 1 period, Table 4). But, during the Deficit 2 period, relative increase in stem height and diameter in $\mathrm{P}$ plants was lower in comparison with NP (Fig. 1). However, $\mathrm{P}$ plants never reached the height of NP plants (Fig. 1). This led to an overall more compact plant architecture, with a lower height:diameter ratio of $\mathrm{P}$ compared with NP plants throughout the study (Fig. 2). Each water-deficit treatment reduced the growth rate since the prior deficit period, but the final result was only a slight reduction in height and diameter (Fig. 3), and no change in growth habit such as that observed with the $\mathrm{P}$ treatment. There was no effect of PA on relative increase of TSA or root hair area. However, PA did increase the relative rate of TRL growth during the PA treatment period (Fig. 4).

There was no interaction between water deficit and PA nor main effect of water deficit for leaf chlorophyll index values on any collection date. However, PA had an effect on leaf chlorophyll index at 19 and $46 \mathrm{~d}$ after the PA treatment ended (59 and 86 DAT). By $19 \mathrm{~d}$ after restoring full irrigation, the $P$ plants had greener leaves, with a respective mean and standard error for the P treatment of 32.6 and 0.45 , respectively, and mean and standard error for the NP treatment of 25.6 and 0.73 , respectively. This difference was not found during Deficit 2 (68 d after the end of priming, 108 DAT) or on any other subsequent dates (data not shown due to nonsignificance).

There were no interactions between deficit and PA for $A, E$, or $g_{\mathrm{S}}$ on any measurement date. The priming effect increased all three variables, $A, E$, and $g_{\mathrm{S}}$, during the month before Deficit 1 , but not at any point thereafter (Fig. 5). The water-deficit treatments decreased $A, E$, and $g_{\mathrm{S}}$ during the imposition of the deficits themselves; however, once the deficit was relieved and water application restored, $A, E$, and $g_{\mathrm{S}}$ of Deficits
1-3 returned to levels similar to that of the Deficit 0 (nonstressed) treatment (Fig. 6). There were no effects of PA or water deficit on $A, \mathrm{E}$, or $g_{\mathrm{S}}$ at the final measurement date.

During Deficit 1, PA and SWT affected daily water loss (Table 5), but there was no interaction between these two factors. Thus, priming impacted water use across the range of SWTs between 0 and $-55 \mathrm{kPa}$, and this impact was constant over the range from low to high SWT (Fig. 7). This led to a cumulative water loss in P plants of more than three times that of NP plants during the Deficit 1 period (Fig. 8).

\section{Discussion}

The temporary increase in $A, g_{\mathrm{S}}, E$, and leaf chlorophyll index induced by PA was similar to the findings from a previous experiment using similar priming treatments in papaya (Vincent et al., 2015), but in the present study, observations continued 4 months longer after the PA treatment than the previous experiment. Similar to the results of the present study, de Lima et al. (2015) observed that, when irrigation was supplied to the previously dried portion of the root system in a partial root-zone drying (PRD) treatment, leaf elongation over a 6-d period increased such that PRD leaves had recovered all of the length lost during the drying period over the previous 2 weeks. On the other hand, Mahouachi et al. $(2006,2007)$ described deficit induction and recovery in papaya without observing compensatory growth. Those studies found a complete recovery of $A$ upon rewatering. Although Mahouachi et al. $(2006,2007)$ measured soil volumetric water content, they did not assess soil water potential, which prevents direct comparison of plant-relevant soil moisture conditions among studies using different substrates. However, while we did observe recovery of $A$ following the deficit treatments, compensatory growth did not occur. Thus the level of water stress imposed in the deficit treatments in the present study may have been similar to the level in Mahouachi et al. (2006, 2007), whereas the response after PA appears to be similar to the PRD treatment in de Lima et al. (2015). These findings reinforce the qualitative difference between plant response to mild and severe deficit stresses (Lichtenthaler, 1998).

Following the PA treatment in the current study, $A, g_{\mathrm{S}}, E$, and plant water loss increased; but these increases in physiological variables were short term, lasting about 6 weeks after the end of the priming treatment, regardless of the imposition of a subsequent drought stress. The increases in $E$ led to increases in DWL; with the nearly 3-fold increase in DWL being sufficient to reduce soil moisture despite the relatively large pot size $(37.9 \mathrm{~L}$ for plants growing from 25 to $45 \mathrm{~cm}$ in height during this period) and daily watering. Based on the linear model, greater plant water use of P vs. NP plants would be predicted at all SWT levels; however, there were few data points at tensions greater than $-40 \mathrm{kPa}$, thus estimates at higher tensions are questionable. The concurrent increase in $A$, relative growth rate of stem diameter and TRL, water use, root:shoot, and root:LA hint at a shared mechanism between increases in plant water use, net photosynthesis, and root partitioning of carbohydrates. Increased water use likely resulted from enhanced water uptake from increased root length and root mass relative to leaf area. Increased root access to water may have increased plant $\mathrm{N}$ uptake, resulting in elevated photosynthetic capacity. Likewise, the link between increased sink demand for assimilates, such as root allocation, and induced upregulation of net assimilation has been documented in other species, including citrus (Citrus paradisi Macf. and Citrus aurantium L.; Syvertsen, 1994).

The change in root:shoot partitioning occurred during the priming period without reducing total growth of the plant or any plant organ. Although the TRL of the P plants began below that of the NP plants, this occurred as an artifact of sampling, as no treatment had been imposed, and plants had been blocked based on stem diameter. Still, $\mathrm{P}$ increased relative growth of TRL, eliminating the initial differences in root length (Fig. 4). In addition, the increases in TRL without increases in TSA indicate that $\mathrm{P}$ plants were preferentially allocating root growth to root extension, rather than to root area. This result is similar to those of increased rooting depth in a PA study of peanut, which was hypothesized to be a drought response mechanism to increase root access to water deeper in the soil profile (Rowland et al., 2012). However, this mechanism is only beneficial in deep soils under moderate or short-term soil water deficits, cases in which greater rooting depth actually confers increased access to soil water (Tardieu, 2012).

Some PA effects did remain through the end of the study. Although P did not affect 
stem diameter or final DWs, stem height and the height:diameter ratio remained different throughout the study. Thus, $P$ had a long-term impact on plant morphology, without reducing growth. Likewise, root:LA ratio differences remained at the end of the study. Similar findings were reported recently in olive (Olea europaea L.), in which an RDI treatment resulted in shifted partitioning from vegetative tissue to yield, and shortened internode length (Rosencrance et al., 2015). These morphological adjustments may be conducive to water-deficit tolerance, as increased root allocation and lower, more compact aboveground growth have been associated with improved drought tolerance in some cases (Sack et al., 2003). However, because these changes in morphology and carbon allocation did not result in maintenance of growth or $A$ under any of the deficit treatments, they are likely to be beneficial only under more moderate deficits (Tardieu, 2012). Water-deficit treatments in this study surpassed any drought tolerance conferred by the shorter, more compact plant morphology. Thus, appropriate subsequent studies would be to address a range of durations or severities of water deficit following PA.

Despite the short-term impacts on root: shoot partitioning and leaf gas exchange,
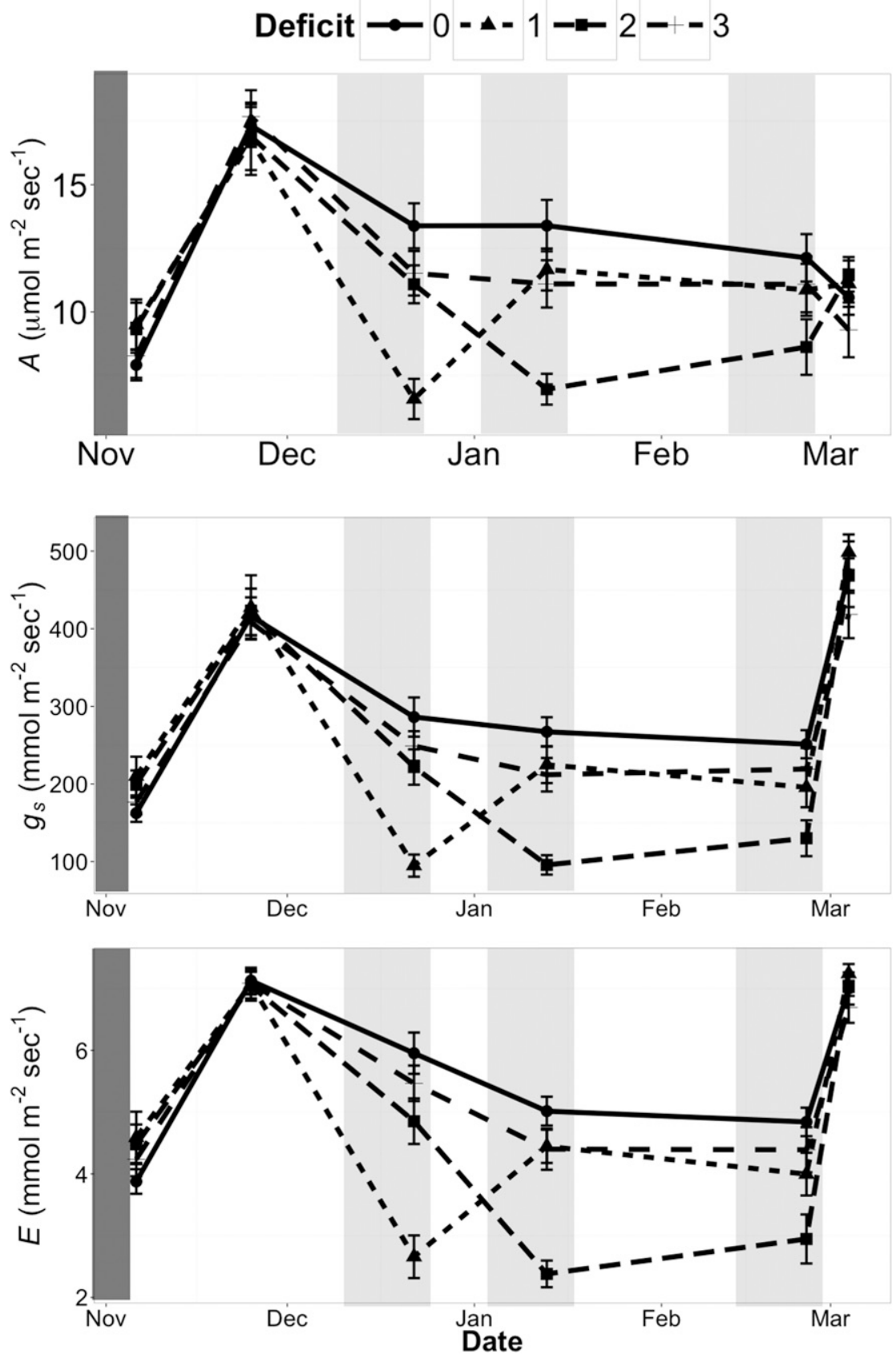

Fig. 5. Gas exchange variables of 'Red Lady' papaya plants with or without a primed acclimation treatment over three water-deficit periods. Data represent deficit and nondeficit treatments combined. Priming treatment consisted of 3 weeks at soil water tension of about $-20 \mathrm{kPa}$ from 20 Oct. to $12 \mathrm{Nov}$. Deficit periods are designated by gray rectangles. Error bars represent standard error $(\mathrm{n}=6)$.

and long-term impacts on morphology, PA did not appear to impact tolerance to the severe deficit periods, regardless of the length of the interval between the PA treatment and the water-deficit treatments. According to our hypothesis, stress memory would include changed stomatal sensitivity and consequent impacts on $A$ or maintenance of root or other organ growth relative to unprimed plants under subsequent stresses (Pastor et al., 2013). We conclude that, despite long-term impacts on morphology, short-term conditions dominate papaya physiological functions, and that PA does not activate any obvious mechanisms of long-term stress memory in papaya. The lack of enhanced stomatal sensitivity of papaya after PA may be linked to its already naturally high stomatal control, which allows it to maintain beneficial leaf water potentials under severe root-zone water deficits regardless of preceding conditions (Mahouachi et al., 2006; Vincent et al., 2015). Another potential explanation for the lack of impact of PA on drought tolerance is that the root:shoot ratio and leaf gas exchange effects of PA may have worn off by the time the most severe deficits occurred.

Another important mechanism linked to stress memory can be lasting changes in root architecture. In the present study, there was no impact of increased root allocation and water use on water-deficit tolerance, possibly due to the increased metabolic costs associated with increased root growth. These costs can be even more detrimental under water deficits, such that greater root allocation can be maintained at high soil moisture, but not under water deficits. The limited soil volume imposed by a potted study could compound this effect, although a large pot size was chosen to minimize this limitation, and no root binding was observed during destructive sampling. Although, increased root:shoot ratio is often cited as a drought tolerance mechanism, this is only true if increased root allocation increases access to water or nutrients, which may not occur with limited soil depth or in pots (Tardieu, 2012). In this study, the pots allowed $\approx 45 \mathrm{~cm}$ of depth, and $30-\mathrm{cm}$ radius from the stem to the edge of the pot. Marler and Discekici (1997) described the majority of the roots of 'Red Lady' papaya occurring within this depth range, though roots explored up to $60 \mathrm{~cm}$ around the plant. In the present study, greater root extension would have led to more thorough exploration of the same volume, resulting in higher water uptake under sufficient soil moisture, but not under extreme deficits, which is consistent with the root growth and water use observations.

Like the effects of $\mathrm{P}$, impacts of the waterdeficit treatments appeared to be temporary. Although water-deficit treatments reduced final total DW relative to the control, the physiological impacts were temporary. Thus, the reductions in organ DW likely resulted from short-term reductions in $A$ during the 
deficit period. Likewise, the leaf chlorophyll index was not decreased by water-deficit treatment. This combination of results leads us to conclude that papaya stress acclimation relies on rapid short-term acclimation responses, which is consistent with other studies of papaya ecophysiology, in which current day conditions had the greatest impact on leaf gas exchange of papaya (Clemente and Marler, 1996; Marler and Mickelbart, 1998; Vincent et al., 2015). In addition, Clemente and Marler (1996) found that $g_{\mathrm{S}}$ responded in a matter of seconds to changes in irradiance, and Marler and Mickelbart (1998) found different gas exchange and chlorophyll fluorescence responses of drought-stressed plants on cloudy as compared with sunny days. These studies all support a fairly rapid plasticity in papaya drought responses, possibly resulting in an overall short-term memory response to these stresses.

Papaya physiological and growth responses to PA and deficit treatments were qualitatively different. $\mathrm{P}$ increased subsequent $A, E, g_{\mathrm{S}}$, leaf chlorophyll index, and the root:shoot and root:LA ratios without reducing total or organ DWs. Contrary to the PA effect, the water-deficit treatments reduced total and organ DWs, with no subsequent increases in physiological variables observed. In terms of growth allocation, water deficits reduced both root:shoot and root:LA, likely due to disproportionate reductions of root DW relative to other organ DWs. This difference between the nature of PA and the deficit effects confirms contentions by other authors that, although the degree of plant stress severity may be continuous, responses of the same plant to stresses of different severities can be qualitatively different (Lichtenthaler, 1998; Tardieu, 2012). Further, although the current study was not repeated, these results are highly consistent with the results found previously by the same authors in a different location under different conditions (Vincent et al., 2015). Likewise, similar results from other studies described above, particularly de Lima et al. (2015) and Mahouachi et al. (2006, 2007) add credence to the conclusions that 1) mild water deficits induce compensatory growth in papaya upon recovery of rootzone moisture, and that, 2) although papaya $A$ and $g_{\mathrm{S}}$ recover upon resumption of sufficient soil moisture after severe deficits, compensatory growth is not observed.

The present study calls into question the applicability to perennial species of assumptions regarding PA of annual crops. Awal and Ikeda (2002) posited that plant species with high degrees of plasticity were likely candidates for water-deficit priming, and this hypothesis held with peanut (Rowland et al., 2012). However, papaya appears to be an exception to this rule, and shows no functional stress memory, while acclimating quickly to prevailing conditions (Buisson and Lee, 1993; Clemente and Marler, 1996; Marler and Clemente, 2006; Vincent et al., 2015). This begs the question
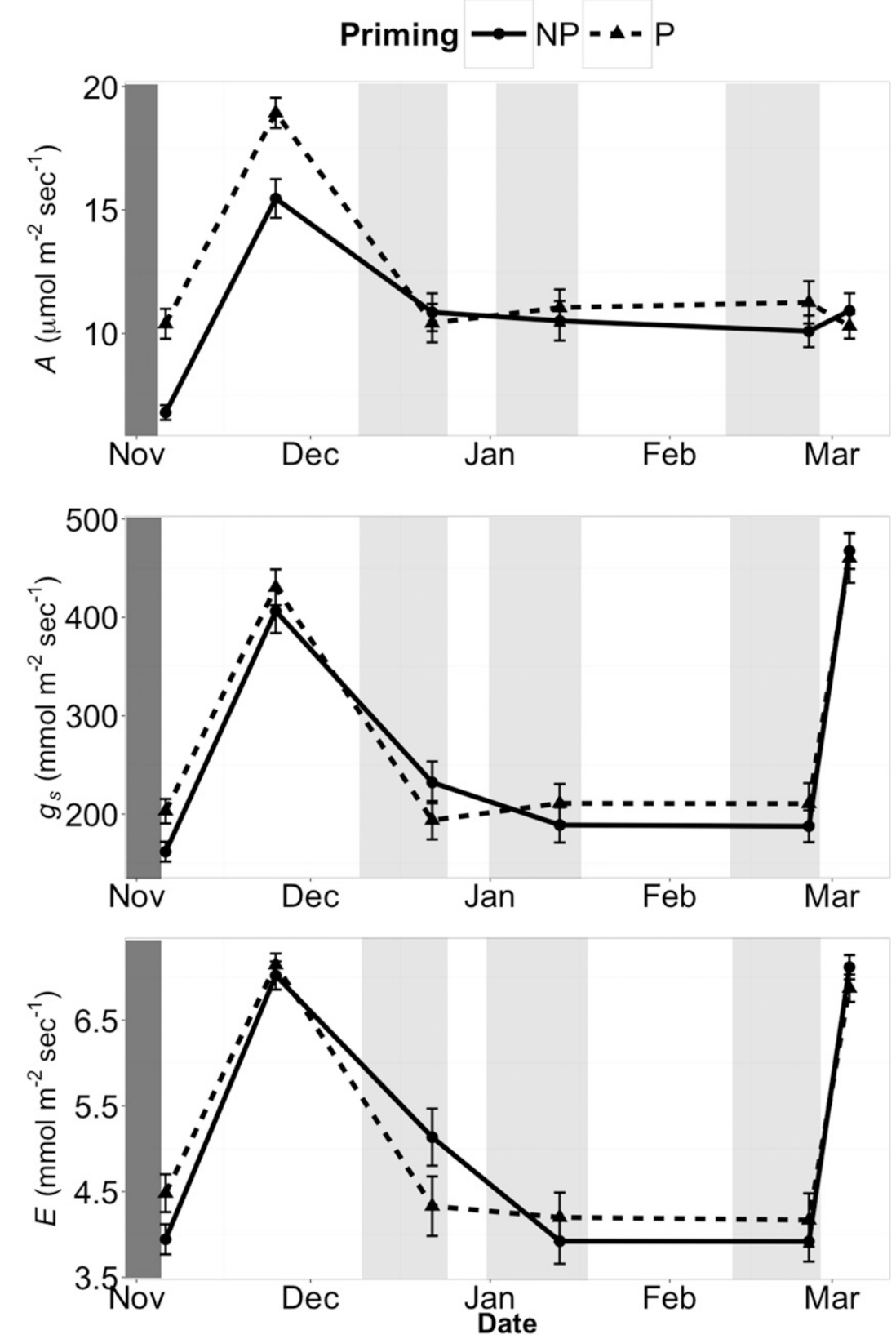

Fig. 6. Gas exchange variables of 'Red Lady' papaya plants treated with different timings of water deficit. Data represent primed and unprimed treatments combined. Water-deficit treatments consisted of no water until soil water tension was below $-40 \mathrm{kPa}$ for 1 week. Deficit periods are designated by gray rectangles. Error bars represent standard error $(n=6)$.

of whether the lack of a long-term stress memory is a common characteristic of perennial plants. In potato water-deficit stress memory between generations of potato tubers (Ramírez et al., 2015), but perennials in which stem and root systems persist may have a different set of tradeoffs than tuberous crops. Crisp et al. (2016) observed that stress memory is a disadvantage under some circumstances because the benefit of increased growth under favorable conditions may be greater than the risk of reduced growth under deficit conditions. The difference in tradeoffs, either due to long-term reproductive strategies or to rapid plasticity, may also coincide with differences in stress memory dynamics, and both should be the
Table 5. Linear model for daily plant water loss from primed and unprimed 'Red Lady' papaya for $30 \mathrm{~d}$ of dry-down after end of priming treatment with block as a random variable. Denominator $\mathrm{df}=165$.

\begin{tabular}{lccc}
\hline & df & F value & $P(>\mathrm{F})$ \\
\hline Soil water tension & 1 & 39.07 & $<0.0001$ \\
Priming & 1 & 13.56 & 0.0003 \\
Tension $\times$ priming & 1 & 2.18 & 0.14 \\
\hline
\end{tabular}

subjects of further investigation in perennial crops.

The next step in this line of inquiry is to test PA on papaya under field conditions. Although we did not find evidence that PA can induce improved water-deficit tolerance, PA also did not reduce growth. 


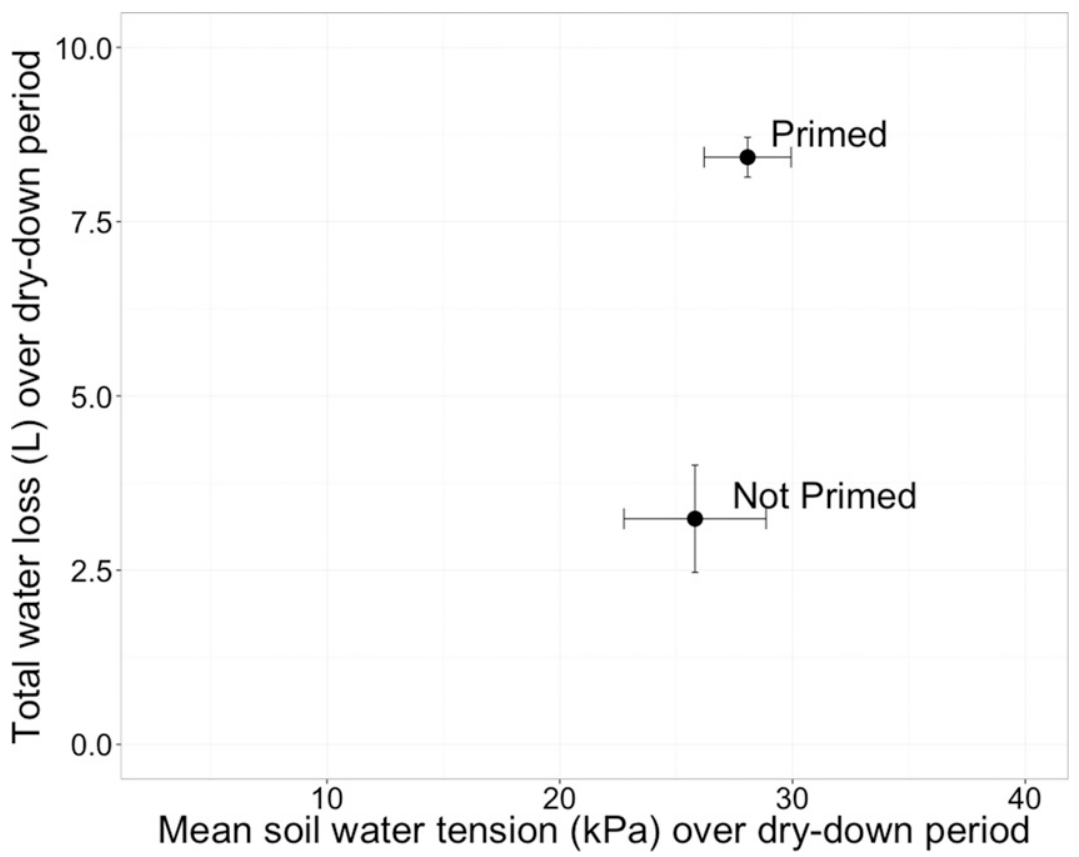

Fig. 7. Total water loss (L) and mean daily soil water tension ( $\mathrm{kPa}$ ) per pot of 'Red Lady' papaya over a 5-week dry-down period after exposure to a 3-week primed acclimation treatment. Error bars represent standard error $(\mathrm{n}=6)$.

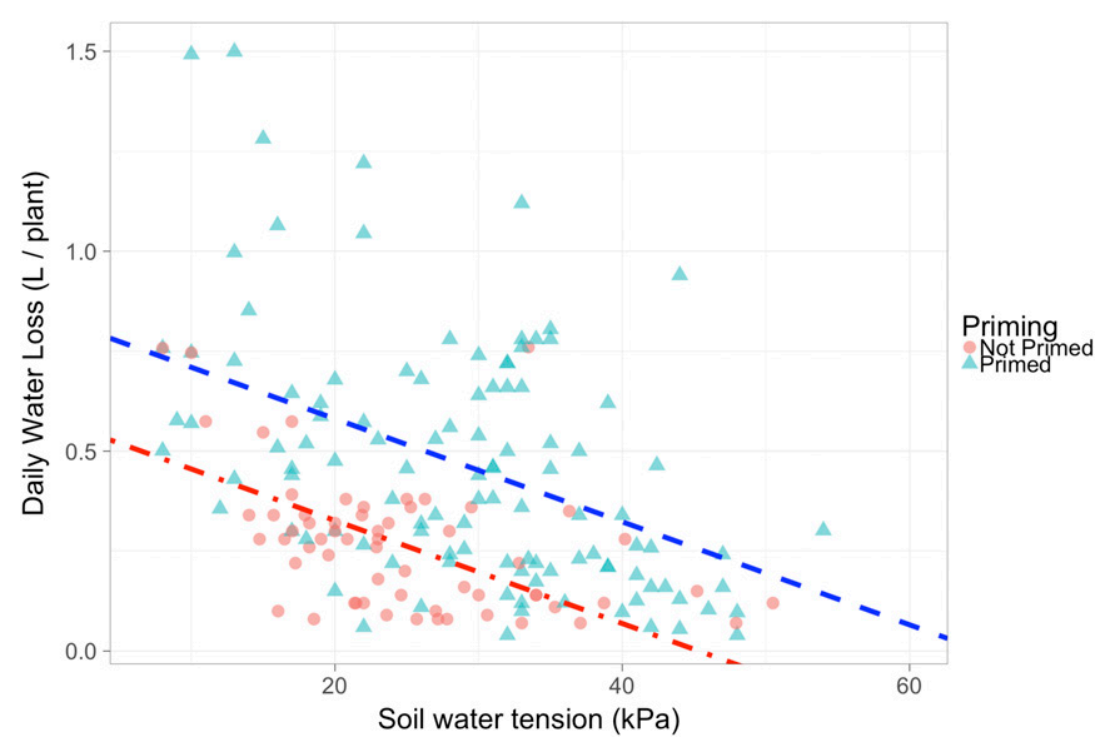

Fig. 8. Total water loss (L) and mean daily soil water tension ( $\mathrm{kPa}$ ) per pot of 'Red Lady' papaya over a 5-week dry-down period after exposure to a 3-week primed acclimation treatment. Lines represent coefficients of linear regression on the same data: dashed blue line represents primed plants and dashed-dotted red line represents unprimed plants. Interaction effects were nonsignificant, thus the slope of both lines is not different, but the intercept was different by $0.25 \mathrm{~L} \cdot \mathrm{d}^{-1}(P<0.0001)$. Marginal $R^{2}=0.62$ and conditional $R^{2}=0.77$

Future studies should focus on determining whether increased plant water use increases long-term irrigation water requirements, or whether it achieves the goal of water conservation.

\section{Literature Cited}

Awal, M.A. and T. Ikeda. 2002. Recovery strategy following the imposition of episodic soil moisture deficit in stands of peanut (Arachis hypogaea L.). J. Agron. Crop Sci. 188:185-192.
Buisson, D. and D.W. Lee. 1993. The developmental responses of papaya leaves to simulated canopy shade. Amer. J. Bot. 80:947-952.

Clemente, H.S. and T.E. Marler. 1996. Drought stress influences gas-exchange responses of papaya leaves to rapid changes in irradiance. J. Amer. Soc. Hort. Sci. 121:292-295.

Crisp, P.A., D. Ganguly, S.R. Eichten, J.O. Borevitz, and B.J. Pogson. 2016. Reconsidering plant memory: Intersections between stress recovery, RNA turnover, and epigenetics. Sci. Adv. 2(2):E1501340 de Lima, R.S.N., F.A.M.M. de Assis Figueiredo, A.O. Martins, B.C. de Deus, T.M. Ferraz, M. Gomes, E.F. de Sousa, D.M. Glenn, and E. Campostrini. 2015. Partial rootzone drying (PRD) and regulated deficit irrigation (RDI) effects on stomatal conductance, growth, photosynthetic capacity, and water-use efficiency of papaya. Sci. Hort. 183:13-22.

de Mendiburu, F. 2015. agricolae: Statistical procedures for agricultural research. $\mathrm{R}$ package version 1.2-4.

Hu, T., S. Liu, E. Amombo, and J. Fu. 2015. Stress memory induced rearrangements of HSP transcription, photosystem II photochemistry and metabolism of tall fescue (Festuca arundinacea Schreb.) in response to high-temperature stress. Plant Physiol. 6:403.

Lichtenthaler, H.K. 1998. The stress concept in plants: An introduction. Ann. N. Y. Acad. Sci. 851:187-198.

Mahouachi, J., A.R. Socorro, and M. Talon. 2006. Responses of papaya seedlings (Carica papaya L.) to water stress and re-hydration: Growth, photosynthesis and mineral nutrient imbalance. Plant Soil 281:137-146.

Mahouachi, J., V. Arbona, and A. Gómez-Cadenas. 2007. Hormonal changes in papaya seedlings subjected to progressive water stress and re-watering. Plant Growth Regulat. $53: 43-51$.

Marler, T.E. and H.S. Clemente. 2006. Papaya seedling growth response to wind and water deficit is additive. HortScience 41:96-98.

Marler, T.E. and H.M. Discekici. 1997. Root development of "Red Lady" papaya plants grown on a hillside. Plant Soil 195:37-42.

Marler, T.E. and M.V. Mickelbart. 1998. Drought, leaf gas exchange, and chlorophyll fluorescence of field-grown papaya. J. Amer. Soc. Hort. Sci. 123:714-718.

Migliaccio, K.W., J.H. Crane, E. Evans, B. Schaffer, Y. Li, and R. Muñoz-Carpena. 2006. South Florida tropical fruit grower perspectives: Water conservation management practices. Fla. Coop. Ext. Serv., IFAS Univ. Fla.

Pastor, V., E. Luna, B. Mauch-Mani, J. Ton, and V. Flors. 2013. Primed plants do not forget. Environ. Exp. Bot. 94:46-56.

Pinheiro, J.C., D.M. Bates, S. DebRoy, and D. Sarkar. 2015. Linear and nonlinear mixed effects models.

Ramírez, D.A., J.L. Rolando, W. Yactayo, P. Monneveux, V. Mares, and R. Quiroz. 2015. Improving potato drought tolerance through the induction of long-term water stress memory. Plant Sci. 238:26-32.

R Core Team. 2016. A language environment for statistical computing. R Foundation, Vienna, Austria.

Rorie, R.L., L.C. Purcell, M. Mozaffari, D.E. Karcher, C.A. King, M.C. Marsh, and D.E. Longer. 2011. Association of "greenness" in corn with yield and leaf nitrogen concentration. Agron. J. 103:529-535.

Rosencrance, R.C., W.H. Krueger, L. Milliron, J. Bloese, C. Garcia, and B. Mori. 2015. Moderate regulated deficit irrigation can increase olive oil yields and decrease tree growth in super high densite 'Arbequina' olive orchards. Sci. Hort. 190:75-82.

Rowland, D.L., W.H. Faircloth, P. Payton, D.T. Tissue, J.A. Ferrell, R.B. Sorensen, and C.L. Butts. 2012. Primed acclimation of cultivated peanut (Arachis hypogaea L.) through the use of deficit irrigation timed to crop developmental periods. Agr. Water Mgt. 113:85-95.

Sack, L., P.J. Grubb, and T. Marañón. 2003. The functional morphology of juvenile plants tolerant 
of strong summer drought in shaded forest understories in southern Spain. Plant Ecol. 168:139-163.

Smith, N.G., S.L. Malyshev, E. Shevliakova, J. Kattge, and J.S. Dukes. 2015. Foliar temperature acclimation reduces simulated carbon sensitivity to climate. Nat. Clim. Change. doi: 10.1038/ nclimate2878.

Syvertsen, J.P. 1994. Partial shoot removal increases net $\mathrm{CO}_{2}$ assimilation and alters water relations of Citrus seedlings. Tree Physiol. 14:497-508

Tardieu, F. 2012. Any trait or trait-related allele can confer drought tolerance: Just design the right drought scenario. J. Expt. Bot. 63:25-31.

Vincent, C., D.L. Rowland, and B. Schaffer. 2015. The potential for primed acclimation in papaya (Carica papaya L.): Determination of critical water deficit thresholds and physiological response variables. Sci. Hort. 194:344-352.
Vincent, C., D. Rowland, C. Na, and B. Schaffer. 2016. A high-throughput method to quantify root hair area in digital images taken in situ. Plant Soil 1-20, doi: 10.1007/ s11104-016-3016-9.

Williamson, J.G. and J.H. Crane. 2010. Best management practices for temperate and tropical/subtropical fruit crops in Florida: Current practices and future challenges. HortTechnology 20:111-119. 